\title{
MORPHOLOGICAL AND DEVELOPMENTAL STUDY OF HUMAN FETAL THYMUS GLAND IN KUMAON REGION
}

\author{
Prerna Singh, AK Singh, Deepa Deopa, Richa Niranjan, Anamika Jaiswal, Vandana Sharma \\ *Department of Anatomy, Government Medical College, Haldwani, Uttarakhand
}

\begin{abstract}
Introduction: A cross sectional study was conducted to observe morphological and developmental changes occurring in thymus gland at various gestational age among human fetuses. The morphometric measurements of thymus is useful in calculating size as intrauterine growth retardation (IUGR) and cellular immune deficiency of infant is associated with a significant decrease in fetal thymic size.
\end{abstract}

Materials \& Methods: This study was carried on medically aborted and stillborn fetuses ( $n=31 ; F=21, M=10$ ), which were obtained from Dr. Sushila Tiwari Memorial Hospital, Haldwani, (Uttarakhand,) with due consent of parents. Fetuses were preserved in $10 \%$ formalin. Thymic gland was dissected out to observe its weight, length and thickness.

Results: Thymus glands were located in superior mediastinum. On gross examination, they were of greyish pink to greyish brown in colour. Most of the glands were bilobed and few were irregular in shape. There was progressive increase in all morphometric dimensions of thymus in relation to gestational age. Growth of right lobe of thymus was comparatively more than of left lobe.

Conclusion: Thymic morphometric parameters in relation to gestational age can be used as reference values in imaging studies in the prenatal and in initial perinatal stages, so we could compare the normal morphology with that of in IUGR and immune deficiency.

Keywords: Fetal thymus gland, morphology, development.

\section{INTRODUCTION}

Thymus gland currently known as one of the primary central lymphoid organ. It is well known as key regulator of immune system because it produces unique environment in which the T-cell precursors (thymocytes) undergo development, differentiation and clonal expansion received from red bone marrow.

In addition to secreting thymic hormones like thymosin, the adult thymus primes thymocytes before releasing them to periphery $[1,2]$. Unlike the other lymphatic organs, the thymus does not filter lymphatic fluid [3]. It appears as a bilobed triangular structure located in the anterior mediastinum, most commonly anterior to the proximal ascending aorta, the pulmonary outflow tract, and the distal superior vena cava before it enters the right atrium. Differentiation of the thymus (during radiological or surgical intervention) from other mediastinal structures, such as lymph nodes or the superior sinus of the pericardium, may be difficult. Therefore, it is important to be familiar with the location, shape, and size of the normal thymus [4].

Thymus gland develops as an epithelial outpouching from the ventral aspect of the $3^{\text {rd }}$ pharyngeal pouch. It starts to descend towards mediastinum and moves caudally forming what is

Address for Correspondence:

Dr. Richa Niranjan, Department of Anatomy, Government Medical College, Haldwani, Uttarakhand.

Mob: 9758512594 Email- niranjanricha@yahoo.co.in 
known thymo-pharyngeal complex. Inferior parathyroid also develops from $3^{\text {rd }}$ pharyngeal pouch. Ventral aspect of $4^{\text {th }}$ pharyngeal pouch give rise to very minor and rudimentary portion of thymic tissue [5]. Descent of heart and caudal migration of aortic sac helps in caudal migration of thymic rudiments [6].

It grows rapidly during the embryonic life and childhood and reaches its maximum size during the puberty. Thereafter, the growth stops and starts involuting gradually until the old age where the gland is often smaller than at birth [7]. The involution of the thymus gland is shown by decrease in the weight of the organ associated with atrophy of lymphoid tissue and replacement by adipose tissue [8]. A reduction in thymus function results in greater susceptibility to tumors, rheumatic disease, growth disorders and general geriatric conditions [9]. The thymus arises bilaterally from the third and fourth branchial pouches and contains elements derived from all three germinal layers. After 14-16 weeks, the thymus grows rapidly and attains its greatest weight in relation to body weight before birth (average 15g) [10]. Studies relating to morphological features and morphometric parameters of thymus gland is limited in comparison to other internal fetal organs. So, further studies on thymus will be useful for researchers.

Ectopic thymic tissue is found in $25 \%$ of the population [11]; small accessory nodules may occur in the neck representing portions which have become detached during their early descent, or the thymus may be found even more superiorly as thin strands along this path, reaching the thyroid cartilage or above. Connective tissue marking the line of descent during early development may, in some instances, run between the thymus and the parathyroids.

Measurements of thymus size appeared to be useful in young human subjects and revealed for instance, that breast fed infant had thymuses on average twice the size of those in formula fed infants [12] and that thymic size at 3 month of age was a powerful predictor of infant mortality in developing country setting [13].

\section{MATERIAL AND METHODS}

This study was conducted in Department of Anatomy, Government Medical College, Haldwani. After ethical committee approval and with due consent of parents medically aborted and stillborn normal fetuses were collected from Obstetrics \& Gynaecology Department, Dr .Sushila Tiwari Memorial Hospital, Haldwani. These fetuses were preserved in $10 \%$ formalin. A sample size of $n=31(F=21, M=10)$ human fetuses were taken ranging from 12 to 38 weeks. The fetuses were measured for crown rump length (CRL), body weight $(W)$, foot length $(F L)$ and pinna length $(P L)$ to confirm the gestational age (GA).

An anterior midline skin incision was given from symphysis menti to xiphisternum. After giving bilateral parasternal incision (resection of costal cartilage) and sternoclavicular disarticulation, thorax was opened. For complete exposure of thymus gland in its natural location for proper recording, lower part of neck was also opened.

The fetal specimen $(n=31)$ were categorized into three groups:

- Group-I- 12 to 18 weeks $(n=12)$

- Group-II-19 to 26 weeks ( $n=10)$

- Group-III- 27 to 38 weeks ( $n=9)$

The weight of whole thymus and separate for right and left lobes were assessed in gross by electronic weighing machine. The length (l), breadth (b) and thickness (t) of whole thymus and separate for right and left lobes were measured in $\mathrm{mm}$ by digital Vernier calipers. Data was analyzed in excel sheet and statistical analysis was done.

\section{OBSERVATIONS AND RESULTS}

The morphometric measurements were analysed by plotting scatter diagram and bar diagram to study correlation with fetal growth. The mean weight, length and breadth of right and left lobes were measured.

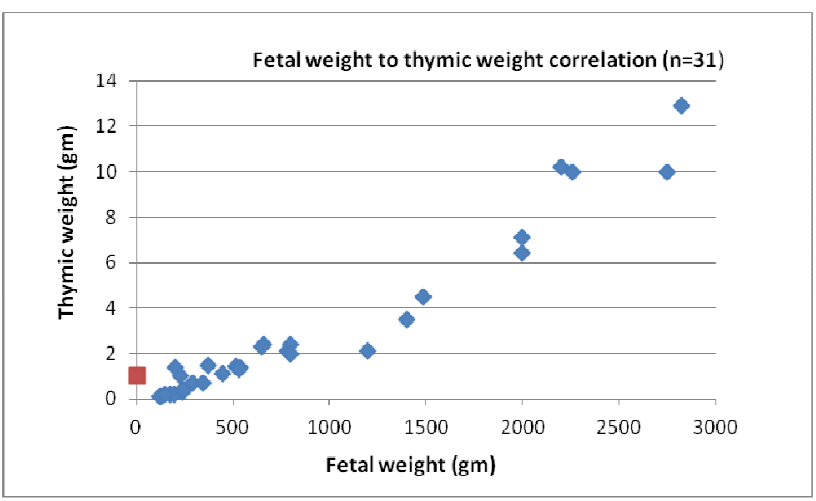

Fig. 1: Scatter diagram showing correlation between fetal and thymic weight 
Study of human fetal thymus gland......

Correlation between fetal $C R L$ and length of right and left lobe of thymus gland was also monitored. The maximum number of values of two variables were seen with increasing trend. Linear relationship was seen between increasing $C R L$ and length of right and left lobes of thymus (Fig. 2\&3).

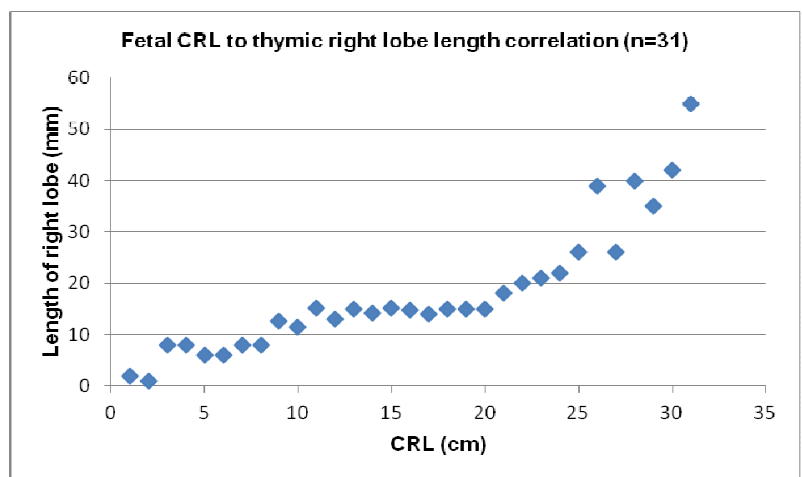

Fig. 2: Scatter diagram showing correlation between CRL and length of right lobe of thymus

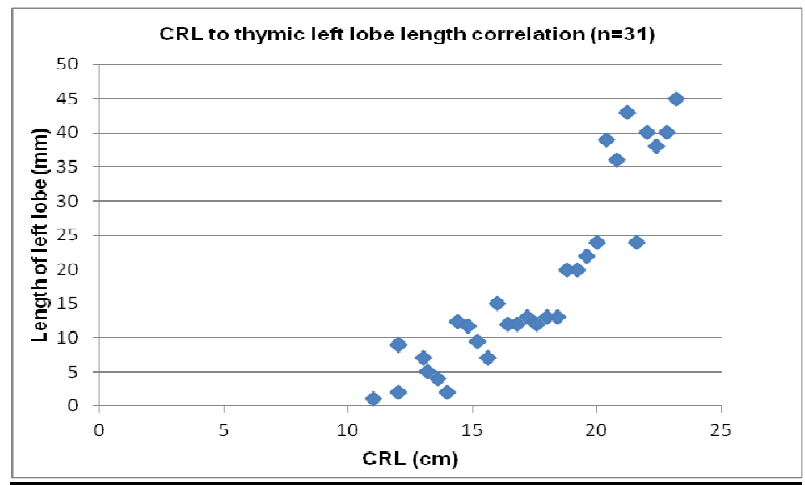

Fig. 3: Scatter diagram showing correlation between CRL and length of left lobe of thymus

The weight of thymus gland ranged from $0.1 \mathrm{gm}$ to $12.9 \mathrm{gm}$. The mean of weight of thymus of group I was $0.475 \pm 0.40$, group II $1.794 \pm 0.49$ and group III 7.41 \pm 3.61 . Comparison among mean weight of three groups was done (Fig. 4). The maximum growth was observed towards the end of gestational age.

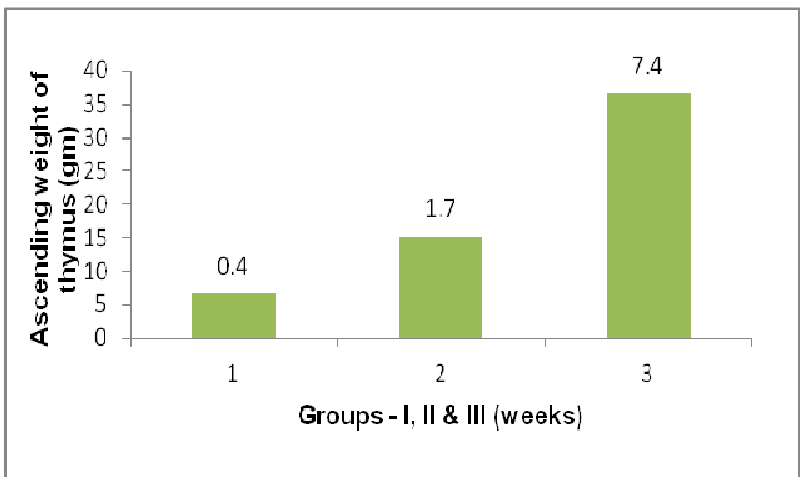

Fig. 4: Bar diagram showing comparison among mean weight of three groups

The length of right lobe of thymus gland ranged from $2 \mathrm{~mm}$ to $55 \mathrm{~mm}$. Comparison of mean length of right lobe among three groups was evaluated i.e. group I has $8.39 \pm 4.31$, group II $15.6 \pm 1.90$ and group III $34 \pm 10.99$ (Fig. 5). The maximum growth was observed towards the end of gestational age.

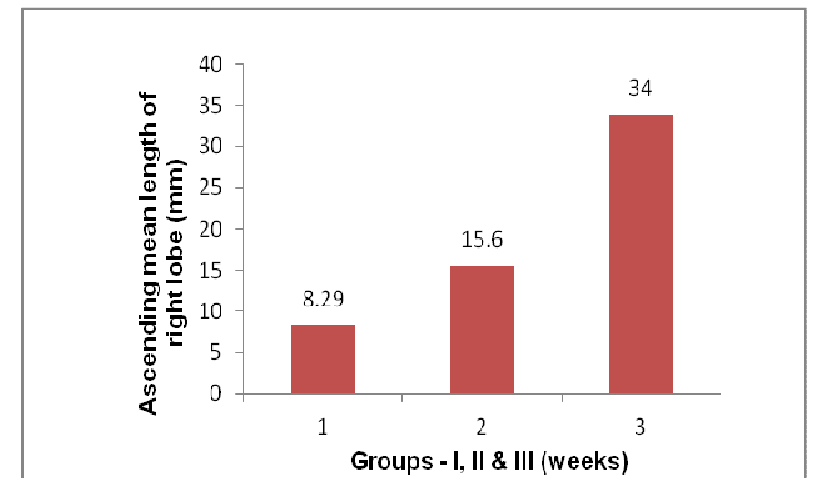

Fig. 5: Bar diagram showing comparison of mean length of right lobe of thymus among three groups

The length of left lobe of thymus gland ranged from $2 \mathrm{~mm}$ to $45 \mathrm{~mm}$. Comparison of mean length of left lobe among three groups was evaluated i.e. group I has 6.61 \pm 3.82 , group II $15.2 \pm 3.91$, group III $36.55 \pm 7.58$ (Fig. 6). It was obvious that length of left lobe grew more than right lobe. 


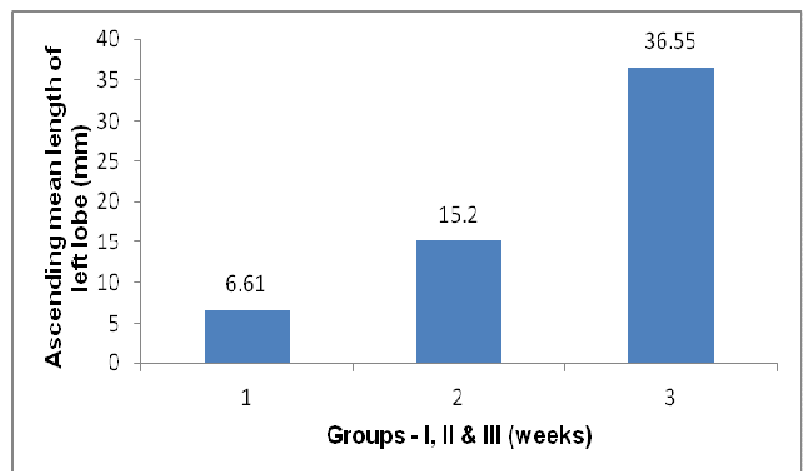

Fig. 6: Bar diagram showing comparison of mean length of left lobe of thymus among three groups

The thymic thickness ranged from $0.5 \mathrm{~cm}$ to 1.5 $\mathrm{cm}$. Comparison of mean thickness of all three groups was done i.e. group I has $0.4 \pm 0.1$, group II $0.5 \pm 0.2$, group III $0.9 \pm 0.4$ (Fig. 7). It was obvious that thickness gradually increased from $0.2 \mathrm{~cm}$ to $1.5 \mathrm{~cm}$ from 12 to 40 weeks of gestation.

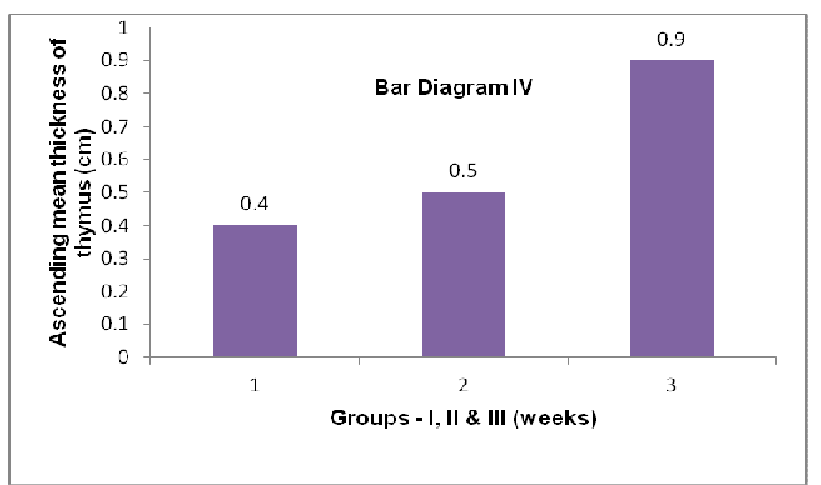

Fig. 7: Bar diagram showing comparison of mean thickness of thymus among three groups

\section{DISCUSSION}

Previous authors observed that after 5 months, rate of development of thymus begins to decrease. They also observed that female fetuses appear developmentally older than male fetuses by analyzing most of the morphological features except thymus and adrenal gland which have continuous growth [14,15]. In present study, the position of thymus gland was in superior mediastinum in which 3 of them were extending above suprasternal notch so 3 fetuses had cervical extension of thymus.
Some studies depicted cervical extension of thymus gland in preterm and post term fetuses, and found the cervical extension, from level above thyroid cartilage till suprasternal notch. They found extension of thymus till diaphragm $[16,17]$. No such observation was found in present study.

The mean length of right lobe of thymus was very much in accordance with the findings of Mamta et al. (2018). According to them, it was $0.98 \pm 0.47 \mathrm{~cm}$ in group I, $1.63 \pm 0.33 \mathrm{~cm}$ in group II and $3.94 \pm 1.05 \mathrm{~cm}$ in group III [17]. In present study, mean length of right lobe was $8.39 \pm 4.31 \mathrm{~mm}$ in group I, $15.6 \pm 1.90 \mathrm{~mm}$ in group II and $34 \pm 10.99 \mathrm{~mm}$ in group III.

Yekeler et al. (2004) measured the maximum cranio-caudal length $31.2 \pm 4.4 \mathrm{~cm}$ in fetus of $31-40$ weeks [18]. Nearly similar value was found in present study in group III which was $39.4 \pm 10.5 \mathrm{~cm}$. This shows progressive growth of fetal thymus from group I to groups II which becomes more rapid from group II to group III.

Weight of thymus as noted by Mamta et al. (2018) was $0.594 \pm 0.336$ in group I, 1.99 \pm 0.88 ) in group II and $8.56 \pm 3.01$ in group III. In present study, the weight of thymus $(\mathrm{gm})$ in group I was $0.47 \pm 0.40,1.79 \pm 0.49$ in group II and $7.41 \pm 3.61$ in group III which shows two times growth in weight of thymus in groups I to group II whereas eight times growth from group II to group III. Therefore, growth in group III fetuses was highly significant.

Waszak and Cieslik (2003) studied the weight of thymus in 20-42 weeks of 3389 fetus. They found the weight of thymus about $9.38 \mathrm{gm}$ in male fetuses and $8.16 \mathrm{gm}$ in female fetuses [15]. In present study, thymus was observed at $12^{\text {th }}$ week of gestation weighing about $0.1 \mathrm{gm}$.

The length of the right lobe showed $2 \mathrm{~mm}$ and left lobe $1 \mathrm{~mm}$ thereby confirming the dissimilarity in the lobulation of the thymus as observed by Scott et al. (2002) [19]. There is increase in all morphometric parameters with increase in gestational age of fetus.

\section{CONCLUSION}

Thymic morphometric parameters in relation to gestational age can be used as reference values in imaging studies in the prenatal stage and in initial perinatal stage.

The morphometric measurements of thymus is useful in calculating size, as IUGR and cellular 
immune deficiency of infant is associated with a significant decrease in fetal thymic size. A basic knowledge about thymic embryology and morphology is also important for diagnosis of ectopic thymic mass and pathological conditions like thymic epithelial tumors.

HIV infection which causes severe loss of Tlymphocytes for which it has become important to understand the role of human fetal thymus as to reactivate cellular immunity.

\section{REFERENCES}

1. Kendall MD. Functional anatomy of the thymic microenvironment. J Anat.1991; 117:1-29.

2. Palumbo C. (2008) Embryology and Anatomy of the Thymus Gland. In: Lavini C, Moran CA, Morandi U, Schoenhuber R. (eds) Thymus Gland Pathology. Springer, Milano. 2008; 4(1): 13-18.

3. Babu DS, Padmavati M, Sailaja V. A study on histogenesis of thymus gland in human fetuses. Int $J$ Anat Res. 2016; 4(1): 2058-2061.

4. Mizuki Nishino, Simon K Ashiku, Olivier N Kocher, Robert L Thurer, Phillip M Boiselle, Hiroto Hatabu. The Thymus: A Comprehensive Review. Radio Graphics. 2006; 26:335-348.5.

5. Hammer JA. Morphology of thymus and probable functions $\mathrm{J}$ Endocrinol. 1921; 5:543-50.

6. Young M, Turnbull HM. An analysis of the data collected by the status lymphaticus investigation committee. J Path Bact. 1931; 34:213.

7. Chavalin V Bharath, Bapuji $P$, Prasad A. Histogenesis of human fetal thymus in $1^{\text {st }}$ and $2^{\text {nd }}$ trimester. JMSCR. 2016; 4 (12): 14376-14381.

8. Shimosato $\mathrm{Y}$, Mukai $\mathrm{K}$. Tumors of the thymus and related lesions. In: Shimosato $\mathrm{Y}$, Mukai K, eds. Atlas of tumor pathology: tumors of the mediastinum, fasc 21, ser 3 .
Washington, DC: Armed Forces Institute of Pathology, 1997; 158-168.

9. Lakshmi KV, Rao BN, Padmini MP. Histo-morphogenesis of thymus in human foetuses. Int J Basic Appl Med Sci. 2012; 2:78-82.

10. Sugavasi R, Devi BI, Sujatha M, Kumar PU, Latha GK. A study on histomorphological features of persistent adult human cadaveric thymus. Int J Curr Res Rev. 2012; 4:74-6.

11. Goldstein G, Scheid MP, Boyse EA, Schlesinger DH, van Vauwe J. A synthetic pentapeptide with biological activity characteristic of the thymic hormone thymopoietin. Science. 1979; 204: 1309-1310.

12. Hasselbalch $\mathrm{H}$, Jeppesen DL, Engelmann MDM, Michaelsen KF, Nielsen MB. Decreased thymus size in formula-fed infants compared with breastfed infants. Acta Paediatrica. 1995; 85: 1029-1032.

13. Aaby $P$, Marx $C$, Trautner $S$, Rudaa D, Hasselbalch $H$, Jensen $\mathrm{H}$, Lissel. Thymus size at birth is associated with infant mortality: a community study from Guinea-Bissau. Acta Paediatr. 2002; 91(6):698-703.

14. Richard E Scammon, The ponderal growth of the extremities of the human fetus. Am J Phys Anthropol. 1930; 15(1).

15. Waszak M, Cieslik K. Sexual dimorphism in developmental dynamics and in progression of morphological features in human foetuses. Folia Morphol. 2003; 62(1):33-39.

16. Krishnamurthy JV, Subhadradevi V. Morphological features of human thymus glands from foetal to old age. Int $\mathrm{J}$ Biol Med Res 3 (2), 1502-1505.

17. Mamta Rani, Nityanand Srivastava, Anuj Jain, Adil Asghar. Study of Morphological features of thymus gland in human foetuses at different age group. IOSR-JDMS. 2018; 17 (7): 3137.

18. Yekeler E, Tambag A, Tunaci A, Genchellac H, Dursun M, Gokcay G, Acunas G. Analysis of the thymus in 151 healthy infants from 0 to 2 years of age. J Ultrasound Med. 2004; 23(10):1321-1326.

19. Scott KJ, Schroeder AA, Greinwald JH Jr. Ectopic cervical thymus: an uncommon diagnosis in the evaluation of pediatric neck masses 2002. Arch Otolaryngol Head Neck Surg. 2002; 128(6): 714-717. 